\title{
PUTTING A LITTLE TLC INTO LEARNING
}

Stella A. Perez

Project SAIL Director/Senior Consultant Online Initiatives

League for Innovation in the Community College

4431 East Ford Avenue

Highley, AZ 85236

Phone: (480) 325-7418; Fax: (480) 396-8101

perez@,league.org

\begin{abstract}
The acronym TLC has typically stood for tender loving care. With the influx of technology into the lives of millions, it might appear that TLC is in short supply; however, the League for Innovation in the Community College has taken this notion of TLC and initiated TLC-Transformational Learning Connections - with the objectives of participation, engagement, and collaboration. TLC's content supports and endorses the promotional reference to Innovation-at-Your-Fingertips through its web-based, anytime-anywhere resource connection between creators of community college innovations and those interested in adopting them. This article presents the seven TLC features-Innovation Express, TLC Forum, Learning Links, Innovation Database, League Connections, Resources on the Web, and the Innovations Online Conference - and the most recent evolution: Innovation Stream or iStream. iStream includes additions such as online conferences, forums, and iStream Radio, which will host a range of programs, interviews, lectures, and seminars with community college leaders.
\end{abstract}

\section{KEYWORDS}

e-learning, e-knowledge, asynchronous learning

\section{ALL I REALLY NEEDED TO KNOW I LEARNED IN KINDERGARTEN. WISDOM WAS NOT AT THE TOP OF THE GRADUATE-SCHOOL MOUNTAIN, BUT THERE IN THE SAND PILE ...}

This year my 5-year old son started kindergarten. Our new world includes drop-off procedures, carpool lanes, snack days, worksheets, immunization schedules, and a line-up of new faces and facilities. We've been in school for only a month now, with me racing to move to the head-of-the-class-on time and on task-while my son engages as a very different kindergarten participant. He is much more reserved, more watchful, and, like the majority of his class, still finding his way in this new environment. What I've come to learn after my month's charge is that the kindergarten approach to learning in my son's community-based school is not that of academic rigor, contextual depth, testing, and assessment. Rather, the primary objectives of my son's kindergarten class are focused on participating, engaging, and collaborating. Navigating these collective processes, with interest, exploration, and a protocol of consideration are the baseline of sound kindergarten success... and much of this is done with the guidance of kindergarten teachers and the traditional notions of $T L C$.

It was Robert Fulghum's 1990 [1] reminder of kindergarten learning that were extrapolated as a popular theoretical approach to creating, building, and thriving in a corporate and policy driven world. Fulghum's 
timely message emphasized the value of relationships and human connections in an imminent era of Internet propulsion, dot.com acceleration, and technological revolution. With many of the ideals of kindergarten learning and Fulghum's sincere truisms on the virtues of sharing and exchange, the League initiated TLC-Transformational Learning Connections in 1996 with the primary objectives of participation, engagement, and collaboration.

Capturing the diverse and unique opportunities to learn, share, and contribute through advancing technologies, TLC was created as a web-based, anytime-anywhere resource connection between creators of community college innovations and those interested in adopting them. Credit for the conception of $T L C$ and the notion of creating this interactive community belongs not only to the highest levels of League leadership, but to those who initiated and contributed to the spirit of $T L C$. The planning, development, and progressive functionality of the initial site belongs to the foundation established by the TLC Resource Coordinators. Credit must also be shared with the developers of innovations who have contributed over 5,000 best practices and model programs to the TLC database, and the visitors who access the $T L C$ website in excess of over 1,000 times a month and have formed a participative audience. Through successive phases and re-invention, $T L C$ has grown to emulate the next generation of technological progress, or the e-learning transformation toward e-knowledge.

In light of the growing branches of web-based research-which include greater access to exponential resources, and new ways to acquire, assimilate, and share knowledge - a growing number of leaders are recognizing the greater value of participation, engagement, and collaboration. The emerging topics of discussion in distance education no longer focus on the hardware bits and bytes of technology, but rather on the fusion of e-learning - through web-enabled participation, engagement, negotiation, and collaboration - and the intersection of education services and technology defined as e-knowledge [2]. In a recent publication, A Revolution in Knowledge Sharing [3], an international collaborative of authors identified e-knowledge as the concept and practice of sharing digital content and context through new mechanisms and marketplaces. To reap the opportunities and advantages of our digital era, educational entities and organizations must change to create environments that dramatically accelerate the sharing and leveraging of knowledge - or re-evaluate their processes of participation, engagement, and collaboration in a networked world. This new era is grounded in "communities of practice" that reduce costs, reinvent or reuse knowledge developments, and create efficiencies of scale for those who adopt new innovations and program developments through the (1) virtual exchange of ideas, (2) best practice research and dissemination, and (3) asynchronous connections to guide implementation practices beyond theory [4].

Higher education's traditional academic practices often defy the kindergarten fundamentals of collaborative exchange because of the reliance on specialized and compartmentalized silos of isolated research. The concepts of knowledge as a fixed resource and the learner as a time- and place-bound dependent participant no longer fit, in form or function, with the developing and emerging landscape of the new digital era. Norris's theory and Revolution conclude that historical practices of knowledge as static and exclusive stand as unsustainable realities of the future of higher education.

As the ideas of knowledge exchange are practiced in a digitized world, so it is that the development and progression of TLC has translated innovations and program developments into a virtual exchange of ideas, best practice research and dissemination. TLC is based on asynchronous connections that offer learning options, participation, and opportunities for collaboration that follow the patterns of kindergarten learning and underscore Fulghum's fundamental message of successful practice and approach-Share Everything, Look, and Be Aware of Wonder. 


\section{A. Share Everything}

As an interactive online community bringing together the resources of League member colleges to provide a dynamic medium for exchanging successful innovations, TLC focuses on improving the specific multipronged missions of community colleges: learning, leadership, student services, technology, and workforce development.

$T L C$ is organized and consolidated to offer quick access to powerful information about successful college innovations as an anytime-anyplace option. Other online resources and search engines are readily available, but do not offer the focused functions of $T L C$, which include:

- Continually updated sources of the latest model programs, best practices, and state-of-the-art technology applications targeting community college innovations and corporate partners focused on community college services;

- Experienced innovators and informed colleges sharing proven practices and ongoing implementation assistance using multiple interactive community exchange tools; and

- Online conference opportunities providing a virtual professional development experience and asynchronous training for remote access to exemplary practices, experienced colleagues, and dissemination of successful innovations.

\section{B. Remember the Dick-and-Jane books and the first words you learned - the biggest word of all-LOOK.}

TLC's content supports seven resource features and endorses the promotional reference, Innovation-atYour-Fingertips. These seven designated features-Innovation Express, TLC Forum, Learning Links, Innovation Database, League Connections, Resources on the Web, and the Innovations Online Conference — offer broad and discrete resources and services.

\section{Innovation Express}

The monthly digital column, Innovation Express (IE), is a concise and comprehensive description of successfully proven innovations with data-driven outcome measures that have been applied in community colleges. Following Fulghum's [1] conjecture-Wisdom was not at the top of the graduate-school mountain, but there in the sandpile - the Innovation Express articles present information on project developments and implementation practices, incorporating successes and failures, obstacles and opportunities, lessons learned, and frequently asked questions from project directors and staff who implement project efforts day-to-day in the sand piles. Authors and contributors are asked to think beyond "the-nice-to-know" information, and share "the-need-to-know" lessons for replicating or adapting innovations to other learning environments. Over thirty unique IE articles are readily accessible online, and include links to project-related websites, program evaluations, and direct email links to the project developers or college contacts for greater detail.

\section{TLC Forum}

As one method of engaging participants through a moderated discussion exchange, the TLC Forum offers anytime, anywhere connections between creators of innovations and those interested in applying or adopting them in new settings. Supporting the functions of an active email listserv, these electronic discussions are open for any level of participation; however, registration is required for posting comments, questions, or information requests. The TLC Forum dialogue themes are introduced monthly, and those sharing innovations invite all registered members to post questions, comments, and ideas. 


\section{Learning Links}

Collaborating and building on the thematic scope of the Innovation Express (IE) monthly articles and the TLC Forum discussions are the TLC Learning Links. These specially selected or recommended supporting web links provide resource connections and complementary references emphasizing the multipronged missions of community colleges. The Learning Links follow the $I E$ themes of learning, leadership, student services, technology, and workforce development.

\section{Innovation Database}

A prominent feature and leading resource of LeagueTLC is the Innovation Database. This online database offers fast and efficient references to print, electronic, and conference sources of innovations and implementation experiences through keywords, titles, or name searches. The Innovation Database contains over 5,000 model programs, best practices, and state-of-the-art innovations relevant to the myriad dimensions of community colleges and critical issues in higher education. Information references and contributors to this unique search engine include the League's $750+$ member colleges, over 100 corporate partners, and decades of conference presentations from the League's annual international conferences focused on innovation and experimentation.

\section{League Connections}

As a prolific source of articles, monographs, and reference publications, the League for Innovation has extended these services beyond the limitations of printed and bound material through League Connections. As an online digital journal, League Connections reaches over 750 member institutions, as well as a host of international colleges and affiliates, and supports connections with ongoing League projects, activities, and events through monthly updates.

\section{TLC Resources on the Web}

The Resources on the Web component of TLC includes access to educational associations, community and technical colleges on the web, and learning resources for educators. Resources on the Web consists of resource links organized by five primary topics, including the League's online database and web search engines, worldwide higher education resources, international community and technical college links, and training resources on the web. Over 25,000 resource links are available through this one comprehensive source, as well as comprehensive descriptions for each reference.

\section{Innovations Online Conference}

With more than two decades of hosting international events, TLC also supports the Innovations Online Conference as a virtual version of the Innovations conference, dedicated to teaching and learning in the community college. The latest technology tools have been integrated to provide a full conference experience, complete with video streaming keynotes and corporate partner presentations. The virtual exhibition hall offers links to product simulations and training materials, special sessions with audio steaming, and high profile forums delivered as Paper Presentation Sessions with live chat opportunities.

\section{BE AWARE OF WONDER}

The primary notions of wonder leading to the success of $T L C$ are merged in the practice of participation, engagement, and collaboration with contributing authors and colleagues in the field. With content and 
resources based on asynchronous research and development, the $T L C$ website brings together a dynamic mix of participants with varying needs, interests, and experiences in a special meeting place and virtual exchange of ideas, services, and resources. The established criterion of selecting proven or data-driven programs and innovations for promotion, and monthly email invitations to participate has drawn interest and expectations from diverse audiences and colleagues for high quality resources and gainful content.

The capabilities for broader resources, deeper levels of participation, and new exchanges and practices in an e-knowledge era have led $T L C$ to another markedly transformational state and a third-generation evolution called Innovation Stream, or iStream. Through a partnership with Seattle Community College District's Department of Internet Services, the League has created iStream as a powerful web-based, multimedia resource that blends the best of League Conferences, publications, services, and networking to meet the unique and diverse styles and need of teaching and learning leaders in higher education. iStream participants will find familiar League resources like TLC coupled with new innovations to widen the professional pathway, including leadership dialogues and people-to-people connections in real time or on your time. iStream offers web access to online conferences, video streamed keynotes, forums, and chats. In addition, the League is offering a new twist on a more traditional frequency - iStream Radio, which will host a range of programs, interviews, lectures, and seminars with community college leaders and lively panel participants.

Subscribers to iStream will also have access to digital versions of all League books, monographs, and best selling publications, such as The Cross Papers: Handbooks on Good Teaching Practices, by K. Patricia Cross; Yes We Can: Study of Developmental Education Programs that Work, by Bob McCabe, and the newly released Faculty Training Tools found in the "Learning Exchange Networks, or LENS Modules. All six training modules offer facilitator resources, workshop guides, and ancillary materials. The module titles reflect themes for instructional and professional leadership, to include:

- Creating a Positive Learning Environment

- Developing Learning Outcomes and Competencies

- Selecting Teaching and Learning Strategies

- Enhancing Teaching and Learning Using Educational Technology

- Classroom Assessment-Formative Strategies

- Instructional Evaluation-Summative Strategies

LENS has an established relationship as one of the most revolutionary and vital resources in community college faculty development. iStream access quickly and inexpensively places this powerful resource in the hands of all full- and part-time faculty on your campus - connecting leaders, learners, and developers with the promise of Innovation at your Fingertips.

\section{SUMMARY}

$T L C$ and now iStream evidence a new dimension in learning, leading, and creating e-knowledge in higher education. True to Fulghum's adage of kindergarten learning, the standing technological developments and evolving $3^{\text {rd }}$ generation resources emulate the quintessential elements of participation, engagement, and collaboration. To satisfy the diverse ways of learning in a digital era, $T L C$, as a first-generation technological resource exchange, stands as a valuable investment and collaborative reminder that...it is still true, no matter how old you are-when you go out into the world, it is best to hold hands and stick together. 
For more information and subscription details, please visit TLC and iStream at www.league.org.

\section{REFERENCES}

1. Fulghum, R. All I Really Needed to Know, I Learned in Kindergarten. $1^{\text {st }}$ ed., New York: Villard, 1990.

2. Wit Capital Corporation. The E-Knowledge Industry, 2-14. August 1999.

3. Norris, D., A. Mason, J., \& Lefrere, P. Transforming e-Knowledge: A Revolution in the Sharing of Knowledge. SCUP: Ann Arbor, MI, 2003.

4. Johnstone, S. M. Signs of the Times: Change Is Coming for e-learning. Educause Review 37(6): November/December 2003. http://www.e-learning.nl/publicaties/marktonderzoek/eknowledge.pdf

\section{ACKNOWLEDGEMENTS}

For John — and all I ever needed to know about love.

\section{ABOUT THE AUTHOR}

Stella Perez is the Project SAIL Director and Senior Consultant of Online Initiatives for The League for Innovation in the Community College. Her work includes review and design of League website content and contributions, as well as direct leadership of Project SAIL (Specialty Asynchronous Industry Learning), a national project promoting the access, exchange, and dissemination of specialized industrydriven programs for community college students, See www.league.org.

Stella has over fifteen years of developing, teaching, and leading technology-based instructional services both in the corporate sector and within community college and university programs. Through her years of experience, she has contributed to the creation of instructional strategies and unique college services based on distance learning initiatives, program assessment, and community resource developments for students, faculty, staff, and administrators. 